\title{
Interactive Technologies Utilization Model for University Relationship Marketing Strategies
}

\author{
Vincent N. Omollo \\ Jomo Kenyatta University of \\ Agriculture and Technology \\ P.O Box 268 - 40200, Kenya
}

\author{
Bathsheba M. Ongaki \\ Kisii University \\ P.O Box 408 - 40200, \\ Kenya
}

\author{
Peter S. Nyakomitta \\ Jomo Kenyatta University of \\ Agriculture and Technology \\ P.O Box 268 - 40200, Kenya
}

\begin{abstract}
The purpose of this paper was to develop a usage model for interactive technologies for university marketing strategies, using a combination of the task technology fit (TTF) model and the information systems acceptance (ISA) model. Interactive technologies enables the universities to inexpensively engage their customers in one- to- one. Over the years relationship marketing has emerged as a popular new paradigm in marketing. It has been proposed as the newest mainstream school of thought in marketing, beyond the twelve commonly accepted schools, that is, commodity, functional, regional, institutional, functionalist, managerial, buyer behavior, activist, macro-marketing, organizational dynamics, systems, and social exchange. The target population of the study was universities marketing departments within Kisii County. A quantitative research design was adopted and random sampling method was used to select respondents. Data was collected by means of questionnaires. Many universities are increasingly strengthening their marketing strategies by effectively interacting with their customers. This is normally done with the help of interactive technologies, such as interactive telephone, internet and digital technologies, in an integrated manner. However, there exists no model that tries to explain the factors behind the utilization patterns of these gadgets.
\end{abstract}

\section{General Terms}

Modeling, Interactivity.

\section{Keywords}

Linear structural relations (Lisrel), Information Systems Acceptance (ISA), Task Technology Fit (TTF), Relationship Marketing Strategies (RMS), GFI, SRMR.

\section{INTRODUCTION}

Interactive technologies include interactive telephone, internet and digital technologies. Many organizations have implemented these technologies for a number of reasons: these technologies help to reduce costs of conducting transactions; they enhance customer experience; they reduce the turnaround time for service delivery; they increase customer satisfaction; and they also help an organization to maintain a competitive edge over its competitors [1].

According to [2], interaction has usually been considered a defining attribute of all services. The main reason is that services are characterized by simultaneous production and consumption, thereby requiring customer-university interaction. Service has been equated with customer service, that is, service provided in support of the university's core products. However, services are typically broadly defined as 'deeds, processes and performances. Service industries include government, transportation, communications, finance, hospitality, education, retail, computing, and information services.
In their study, [3] noted that it is essential for institutions to move from short-term transaction oriented goals to long-term relationship-building goals. Relationship marketing offers institutions the opportunities to achieve this goal and to build long term relationships with their stakeholders. These relationships are also regarded as a key marketing asset. Both academicians and practitioners have indicated that RM is obviously good for business and yields improved business performance. It is argued that the domain of RM should extend its boundaries to all marketing activities (for example, internal customers, networks, partnerships), instead of the limited dyad model. Firms should build up long-term relationships with students in order to enhance their core competitiveness. Interactive technologies come handy if universities have to achieve these kinds of relationships.

\section{RELATED WORKS}

Relationship marketing is a strategy designed to foster customer loyalty, interaction and long-term engagement. This customer relationship management (CRM) approach focuses more on customer retention than customer acquisition. RM is designed to develop strong connections with customers by providing them with information directly suited to their needs and interests and by promoting open communication. This approach often results in increased word-of-mouth activity, repeat business and a willingness on the customer's part to provide information to the organization [4].

A pleasant addition here is that a recent study by [5] reveals that Universities are interested in building and maintaining relationships with their students. Yet, the scarcity of empirical studies about the RM practices of Universities has led to gaps in understanding how these institutions create and develop relationships with their students.

With the growth of the internet and mobile platforms, relationship marketing has continued to evolve and move forward. This is so because technology opens more collaborative and social communication channels [1]. This includes tools for managing relationships with customers that go beyond simple demographic and customer service data. Relationship marketing extends to include inbound marketing efforts, (a combination of search optimization and strategic content), public relations, social media and application development. Relationship marketing is a broadly recognized, widely-implemented strategy for managing and nurturing a company's interactions with clients and sales prospects.

When optimized, interactive technologies have been shown to have a positive effect on customer service scores along with cost-savings [6]. For example, self-service can lead to high rates of satisfaction because customers can get what they need more quickly and with less effort. As this approach has been adopted by more enterprises the channel has remained steady in terms of usage. 


\section{3. METHODOLOGY}

\subsection{Model Design}

The researchers identified four constructs from the ISA model which they believed, from the available literature, could influence the usage of interactive technologies in marketing strategies. These included compatibility and simplicity (Technology Characteristics), adequate resourcing and Management of the implementation process (Management actions). Figure 1 below shows the various constructs of the ISA model.

According to [7], this model assumes that there are two factors that affect information systems acceptance: technology characteristics (Relative advantage, Compatibility, Simplicity and Trialability) and management actions (Communication of system purpose, Cultural reinforcement, adequate resourcing and Management of the implementation process).

The five constructs that were selected from the ISA model were then used to extend the TTF model, which holds that information technology is more likely to have a positive impact on individual performance and be utilized if the capabilities of the information technology itself match the tasks that the user must perform [8]. Figure 2 below shows the original TTF model.

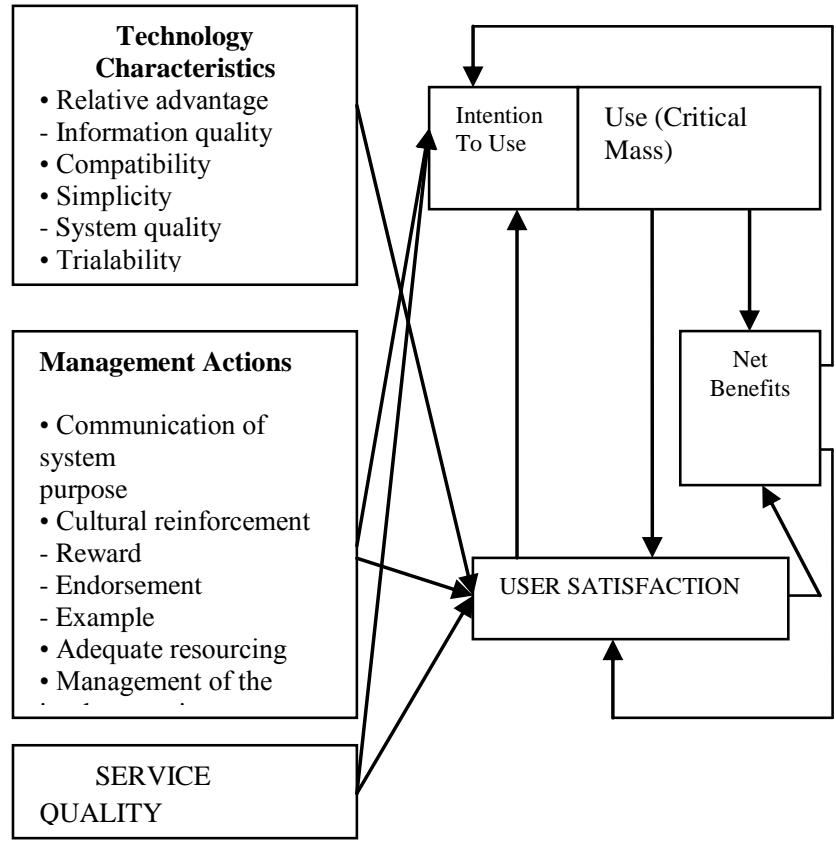

Figure 1: Information Systems Acceptance (ISA)

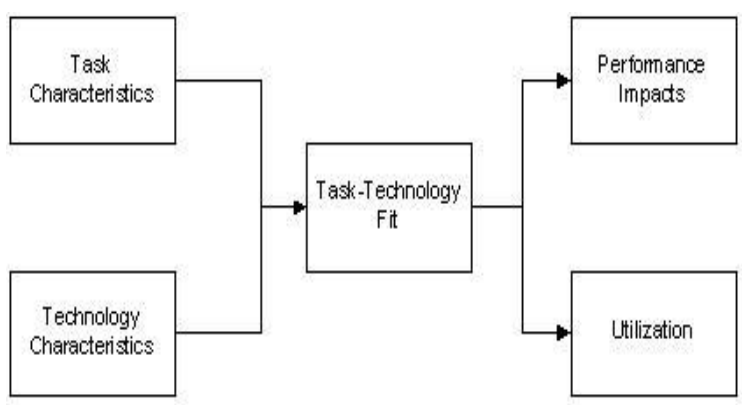

Source: Goodhue and Thompson, (1995)

Figure 2: The Task Technology Fit Model
The interactive technology characteristics included relative advantage, compatibility and simplicity while the utilization component of the TTF was investigated using the remaining three features that is, adequate resourcing, cultural reinforcement and management of the implementation process. Four marketing strategies were identifies as communication, commitment, pricing and networking. These were combined to yield the hypothesized interactive technologies usage model for university relationship marketing strategies as shown in Figure 3 below.

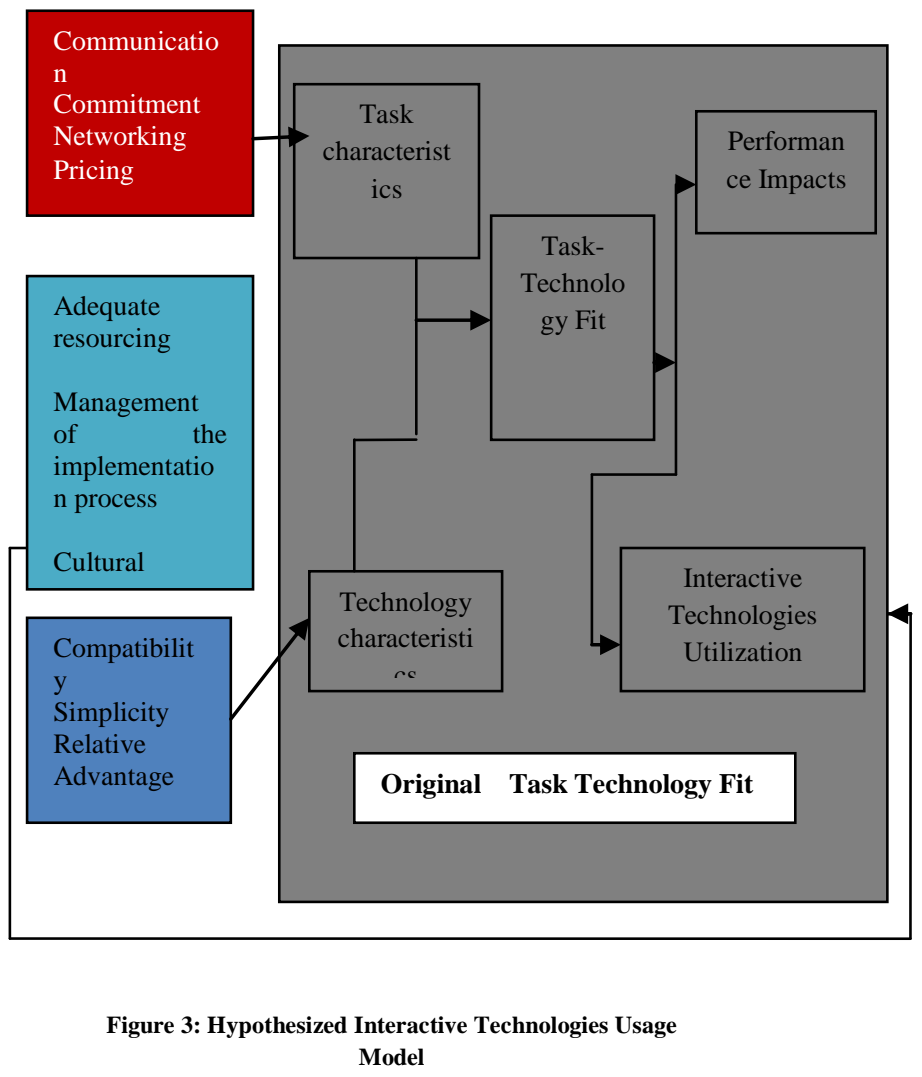

All the ten constructs were used to draft a questionnaire that consisted of four sections: Demographic Data (DD), Task Characteristics (TKC), Technology Characteristics (TNC) and Relationship Marketing Strategies (RMS). Hence TKC, TNC, RMS formed the research latent variables

These questionnaires were then distributed to 50 respondents. Out of these questionnaires, 43 of them were returned, indicating a return rate of $86 \%$ as shown in Table 1 below.

Table 1: Questionnaire Return Rate

\begin{tabular}{|l|l|l|}
\hline Item & $\begin{array}{l}\text { Frequency } \\
(\mathbf{N})\end{array}$ & \% Contribution \\
\hline Returned questionnaire & 43 & 86 \\
\hline $\begin{array}{l}\text { Questionnaire that were } \\
\text { never returned }\end{array}$ & 7 & 14 \\
\hline TOTAL & $\mathbf{5 0}$ & $\mathbf{1 0 0}$ \\
\hline
\end{tabular}

Their contents were coded using a four - Likert scale, ranging from strongly agree to strongly disagree as shown in Table 2 below. 
Table 2: Data Coding

\begin{tabular}{|l|l|}
\hline Scale & Code \\
\hline Strongly Agree & 1 \\
\hline Agree & 2 \\
\hline Disagree & 3 \\
\hline Strongly Disagree & 4 \\
\hline
\end{tabular}

This data was then imported into Lisrel software as shown in Figure 4 that follows. Afterwards, the path diagrams were drawn using the research measurable constructs and latent variables.

\begin{tabular}{|c|c|c|c|c|}
\hline \multirow[b]{2}{*}{ Dr } & \multicolumn{4}{|c|}{ LISREL for Windows } \\
\hline & File & View & \multirow{3}{*}{$\begin{array}{l}\mathrm{C} \text { trl }+\mathrm{N} \\
\mathrm{C} \text { trl }+\mathrm{O}\end{array}$} & \multirow{3}{*}{ 紧| } \\
\hline New & & & & \\
\hline Open... & & & & \\
\hline \multicolumn{4}{|c|}{ Import Data... } & \\
\hline \multicolumn{4}{|c|}{ Print Setup... } & \\
\hline \multicolumn{4}{|c|}{$1 \mathrm{~F}: \backslash$ Research $\backslash \ldots \backslash \mathrm{DATA}$} & \\
\hline \multicolumn{5}{|c|}{2 E:\Graduate $\backslash . . . \backslash$ LatestData_1 } \\
\hline \multicolumn{5}{|c|}{3 E:\Graduate $\backslash . . . \backslash$ LATESTDATA_1 } \\
\hline \multicolumn{4}{|c|}{4 LatestData_1.OUT } & \\
\hline Exit & & & & \\
\hline
\end{tabular}

Figure 4: Importing Questionnaire Data Into Lisrel

\subsection{Model Development}

Model fit determines the degree to which the sample variance-covariance data fit the structural equation model. Model-fit criteria commonly used are chi-square $\left(\chi^{2}\right)$, the goodness-of-fit index (GFI), the adjusted goodness- of-fit index (AGFI), and the root-mean-square residual index (RMR). A significant $\chi^{2}$ value relative to the degrees of freedom indicates that the observed and implied variancecovariance matrices differ. Statistical significance indicates the probability that this difference is due to sampling variation. A non-significant $\chi^{2}$ value indicates that the two matrices are similar, indicating that the implied theoretical model significantly reproduces the sample variancecovariance relationships in the matrix. These criteria are based on differences between the observed (original, S) and modelimplied (reproduced, $\Sigma$ ) variance- covariance matrices [9]. The researchers were interested in obtaining a non-significant $\chi 2$ value with associated degrees of freedom. Thus it was more appropriate to call the chi-square test a measure of badness-of-fit.

In reference to [10], goodness-of-fit index (GFI) is based on the ratio of the sum of the squared differences between the observed and reproduced matrices to the observed variances, thus allowing for scale. The GFI measures the amount of variance and covariance in $\mathrm{S}$ that is predicted by the reproduced matrix $\Sigma$. The adjusted goodness-of-fit index (AGFI) is adjusted for the degrees of freedom of a model relative to the number of variables.

The RMR index uses the square root of the mean-squared differences between matrix elements in $S$ and $\Sigma$. Because it has no defined acceptable level, it is best used to compare the fit of two different models with the same data. There is also a standardized RMR, known as Standardized RMR, which has an acceptable level when less than .05 [9].
All these model fit indexes were used to rate our developed model. The measurable constructs were coded so as to provide a direct determination of the latent constructs. The task technology fit was coded as follows: Adequate resourcing was given code TKC1, cultural reinforcement TKC2 and management of the implementation process TKC3. The interactive technology characteristics were also coded as follows: Relative advantage was coded as TNC1, compatibility was coded as TNC2 and simplicity was coded as TNC3. Finally, relational marketing strategies were coded as follows: Communication was coded as RMS1, commitment was coded as RMS2, pricing was coded as RMS3 and networking was coded as RMS4.

\subsection{Path Diagram}

The ten measurable constructs that were identified above were used to come with the Lisrel path diagram that is shown in Figure 5 below. In this figure, the ovals represent latent variables, technically called Y-variables, while the rectangles represented the measurable constructs, technically referred to as the $\mathrm{X}$-Variables.

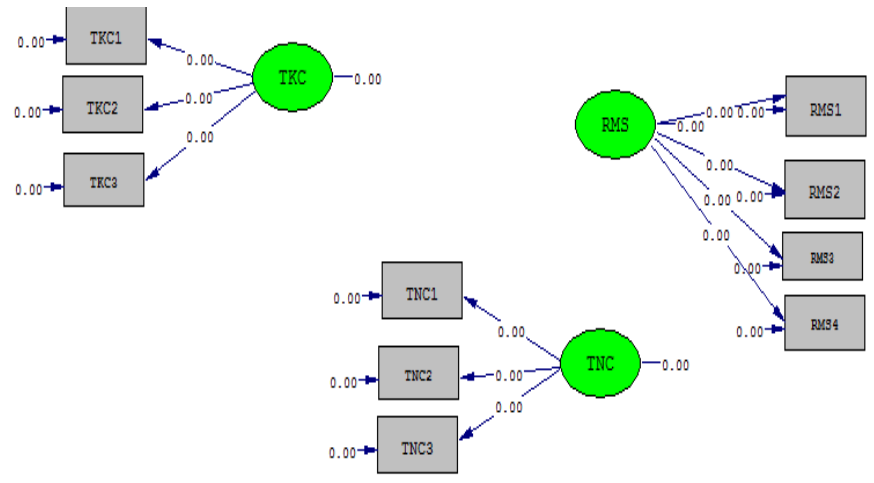

Figure 5: Hypothesized Path Diagrams

The lines emanating from the latent constructs to the measurable constructs were the standardized partial regression coefficients, whose established threshold value is 0.05 [9]. In [11], it is noted that Chi-square / $\mathrm{df}<3$ is recommended.

\subsection{Model Building}

The path diagram above was built by selecting "Build LISREL Syntax" from the menu. This process yielded the following diagram, indicating the values for the path coefficients of every measurable construct. The path coefficients are usually derived from the values of a Pearson product moment correlation coefficient (r) and/or a standardized partial regression coefficient $(\beta)$.

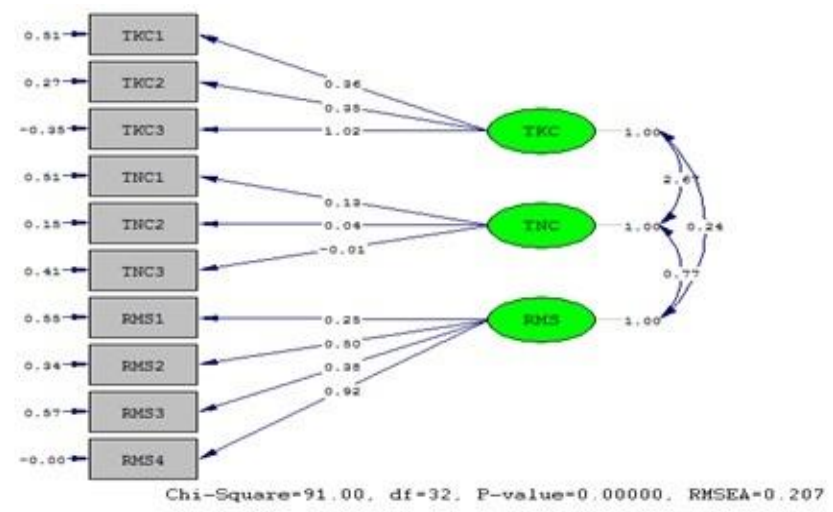

Figure 6: Path Coefficients for Different Measurable Constructs and Latent Constructs 


\section{MODELING RESULTS}

Figure 6 above shows that the obtained Chi-Square was 91.00, degree of freedom (df) was 32, p - value was 0.00000 while the root mean- square error of approximation (RMSEA) was 0.207. As already stated, the threshold value for the standardized partial regression coefficients is 0.05 , that Chisquare / df $<3$ is ideal. From Figure 5, all measurable constructs loaded higher than 0.05 , except constructs TNC3 and TNC2. The value of that Chi-square / df was [91.00/32.00], yielding a value of 2.84375 , which was well below the acceptable level of 3 . Table 3 below shows a summary of these model fit indices.

The curved arrow represents the covariance or correlation between the three latent variables that are employed in predicting the dependent variable. The figure shows that the correlation coefficient between TKC and TNC was 2.67, that between TNC and RMS was 0.77 while that between RMS and TKC was 0.24. The Measurement errors in observed variables were as follows: TKC1 $(0.51), \mathrm{TKC} 2(0.27), \mathrm{TKC} 3$ (-0.25), TNC1 (0.51), TNC2 (0.15), TNC3 (0.41), RMS1 (0.55), RMS2 (0.34), RMS3 (0.57) and RMS4 (-0.00).

\section{Table 3: Model Fit Indices}

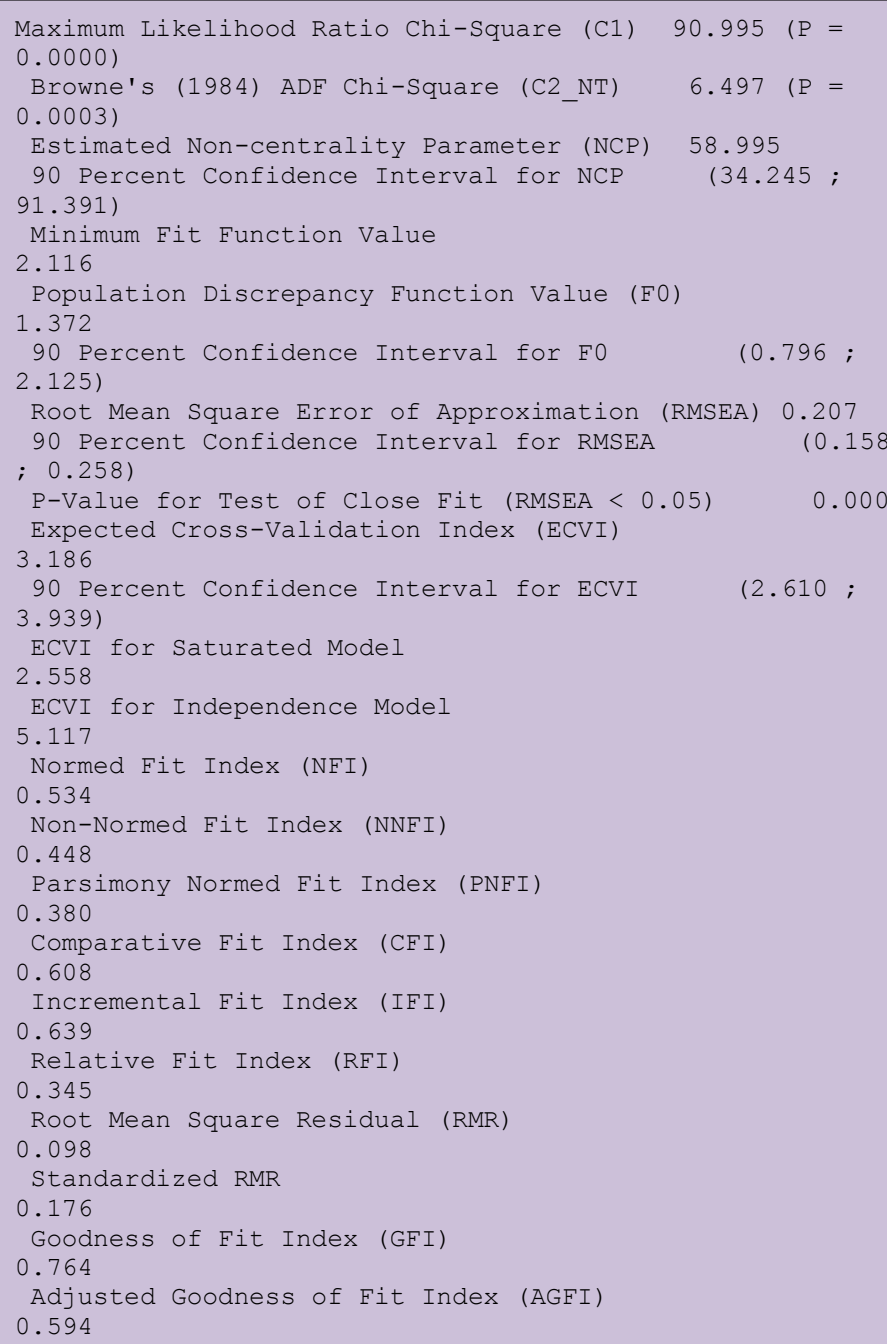

This table shows that root-mean-square residual (RMR) was 0.098 , which was within the acceptable level of $<.08$ and the goodness-of-fit index (GFI) was 0.764 , slightly below the acceptable level of $>.95$. Across this particular set of model- fit indices, the conclusion is that the data to model fit is approaching a reasonable level. To arrive at the final model, the X-variables that had path coefficients $\lambda$, of lower than 0.05 . TNC2 and TNC3 were therefore candidates for elimination because their $\lambda$ 's were 0.04 and -0.01 respectively. Therefore, they were eliminated from the model design as shown in Figure 7.

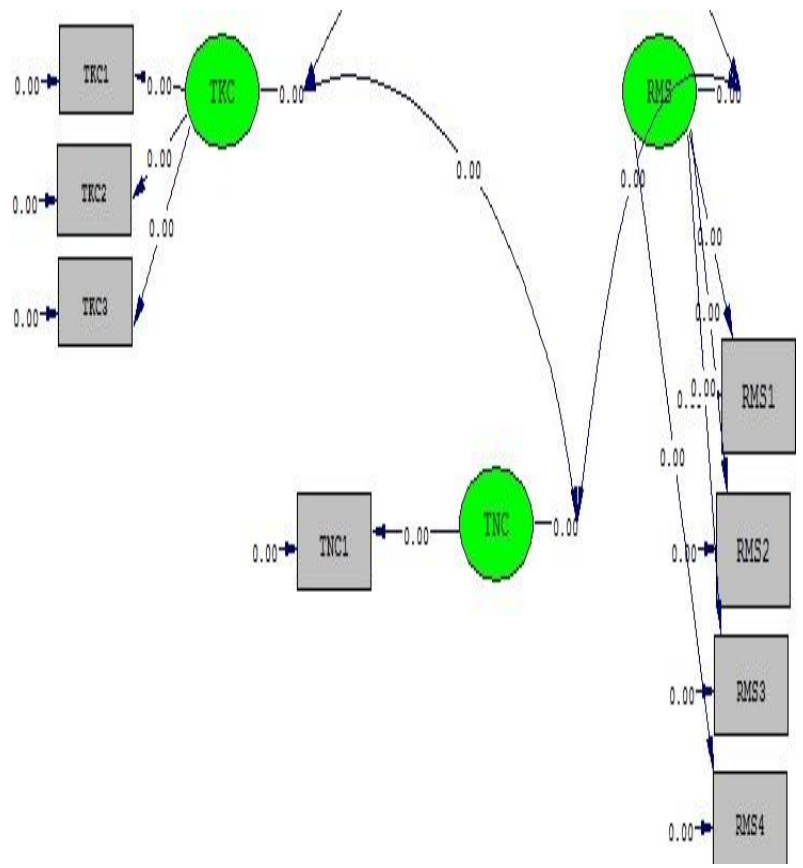

Figure 7: Design of Final Interactive Technologies Utilization Model

The Lisrel Syntax was again build and run to yield the results shown in Figure 8 below. The standardized partial regression coefficients for all $\mathrm{X}$-constructs are now above the cut-off value of 0.05 , with the highest value being 1.02 , for TKC3, while the lowest being 0.12 , for TNC1.

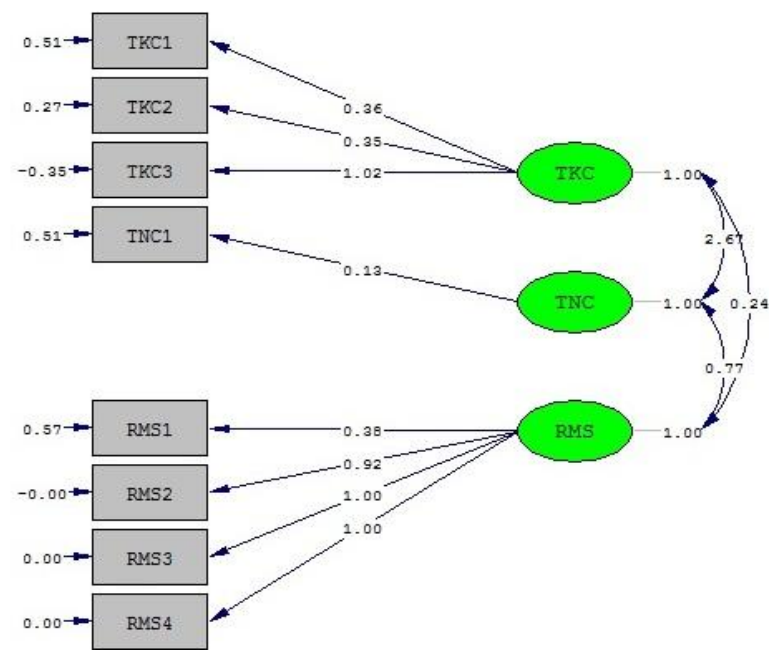

Figure 8: Final Interactive Technologies Utilization Model

Figure 9 shows the final version of the Interactive Technologies Usage Model For University Relationship Marketing Strategies. 


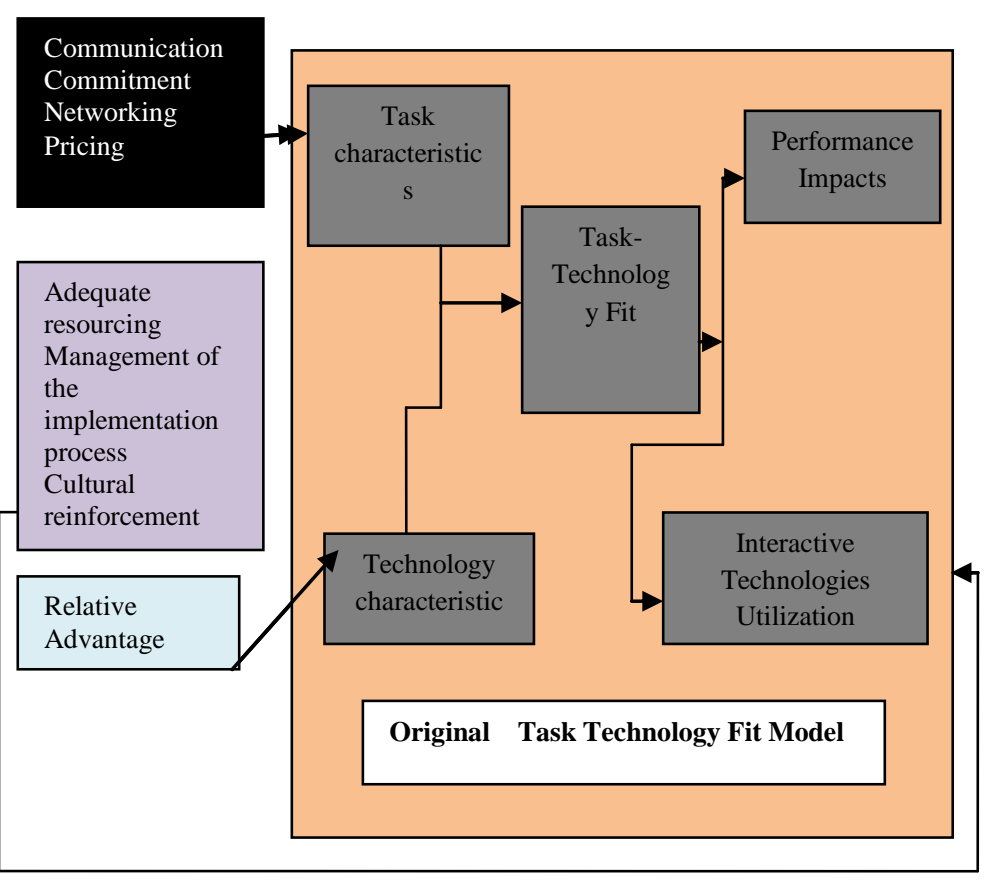

Figure 9: Final Interactive Technologies Utilization Model

\section{DISCUSSION}

The various types of interactive technologies that formed the basis for this study included telephone, internet and digital technologies such as touch screen smart phones and tablets. Their usage has been shown to have positive effects on the relationship marketing strategies, as all of them loaded higher than 0.05 (acceptable level for the path coefficients). Adequate resourcing, cultural reinforcement and proper management of the implementation process are also critical for the successful implementation of the interactive technologies for relationship marketing strategies. On the technology side, it has been noted that relative advantage of the interactive technologies overrides the simplicity and compatibility. The marketing departments in universities are composed of individuals whose primary goals are to woe and retain as many students and other stakeholders (for example, sponsors) to their universities. Therefore any technology that can aid them achieve their primary goals is highly celebrated. The results indicate that they are not very much concerned with simplicity and compatibility, which they deem as technical aspects of the interactive technologies. They better try to understand this technology, however hard it is, because they believe its fruits are worthwhile. Moreover, compatibility only comes in when the interactive technologies prove to be backward compatible with their current platforms. However, most of the interactive technologies such as internet, telephone, touch screens and tablets are compatible with most mobile platforms such as blackberry, android, windows phones, and also computer platforms such as windows XP, windows Vista, windows 2007 and windows 2008. One only needs to upgrade, for example to a higher .NET framework to use the new emerging interactive technologies. Hence from the utilization front, this study has demonstrated that relative advantage is more vital compared to the technology technical aspects of simplicity and compatibility.

The findings of this study fit well with the findings of [12]. In her papers, she found out that internet users perceived online video platforms to be better (because of its interactive nature) than television in many technology and content-related attributes. Her results also suggested that video content quality, interactivity, and storage capability of online video platforms contribute to improving the overall perception of the relative advantage.

\section{SUMMARY}

The study on the development of an interactive technologies utilization model for university relationship marketing strategies was completed successfully. From this study, it was noted that universities use tools such as communication commitment, networking and pricing for their relationship marketing strategies. The success of these strategies was found to be influenced by factors such as: adequate resourcing, proper management of the implementation process and cultural reinforcement. Relative advantage of the interactive technologies themselves was also established to be significant in the utilization of these technologies for marketing purposes.

The quantitative approach that was followed enabled the researchers to carry out statistical analyses such as regressions, goodness of fit index, root-mean-square residual, root mean- square error of approximation and correlations among the research constructs. The results of these analyses were employed to uphold some constructs as others were dropped, depending on their relative loading with reference to the theoretical established values.

\section{CONCLUSIONS}

Interactive technologies can be implemented in a wide diversity of platforms and applications encompassing nearly all areas of technology. These technologies promote dialogic communication. This form of communication permits marketing departments to build long term trust and cooperation with their clients. This plays a decisive role in building relationships. Universities also employ interactive media to go further than basic marketing and develop more positive behavioral relationships. These relationships, coupled with communication, pricing, commitment and networking, all of which are enhanced by interactive technologies, lead to improved marketing process. The internet directly promotes communication and networking, which are key relationship marketing strategies. With the use of internet, universities can reduce their marketing costs (for example by posting advertisements online instead of physically visiting their clients) and hence this cost reductions can be passed to their clients in term of lower pricing. Commitments are also boosted by interactive technologies as tasks can be accomplished within a short time, with little costs.

The developed Interactive Technologies Usage Model For University Relationship Marketing Strategies is ideal in enhancing the marketing efforts of the universities marketing departments. This is so because it takes into account the user tasks features, the interactive technologies characteristics and management issues into consideration and provided an amalgamated model that better explains the factors that promote the utilization of interactive technologies in relationship marketing.

\section{REFERENCES}

[1] A. Zakaria and M. Nidal (2010), "Effect of Electronic Interactive Technologies Usage on Services Marketing Activities Empirical Study on Banking Sector in Jordan”.

[2] R. Bolton (2009), "Interactive Services: A Framework, Synthesis and Research Directions". 
[3] E. Duddy and A. Revzan (2007), "Marketing : An Institutional Approach", 2nd Edition, New York, McGraw-Hill Book Company.

[4] Sheth, Jagdish, David, Gardner, Dennis and Garrett. (2008), "Marketing theory: Evolution and evaluation", New York: John Wiley.

[5] Payne, Adrian (2010), "Handbook of CRM: Achieving Excellence in Customer Management", ButterworthHeinemann, Oxford.

[6] H. Karoline (2014), "Interactive Technology. Traditional Practice", Nordic Journal of Digital Literacy.

[7] S. Megan (2014), "Explaining And Predicting Information Systems Acceptance And Success: An Integrative Model".

[8] Cane, Sheila, McCarthy, Richard and Halawi and Leila (2010), "Training Military Commanders with
Simulation: A Phenomenological Study of TaskTechnology Fit", Journal of Computer Information Systems, Volume 50, Issue 3, 33-40.

[9] G. Richard (2010), “A Beginner's Guide to Structural Equation Modeling", Third Edition, Taylor and Francis Group, LLC.

[10] G. Ganzeboom (2010), "LISREL: Interpreting the LISREL output",

[11] K. Joreskog and T. Van (2010). "LISREL: A General Computer Program for Estimating a Linear Structural Equation System Involving Multiple Indicators of Unmeasured Variables (RB-72-56)", Princeton, NJ: Educational Testing Service.

[12] M. Silvia (2012), "Relative Advantages Of Online Video Platforms And Television According To Content, Technology And Cost-Related Attributes". 